\title{
Delay in diagnosis and treatment among registered TB patients in Directly Observed Treatment Short Course cum Designated Microscopy Centres in South Delhi
} \section{Arunraj Kamaraj ${ }^{1}$, Manish Kumar Goel ${ }^{2}$, Jyoti Khandekar ${ }^{3}$, Khalid Umer Khayyam ${ }^{4}$, Sanjeev Kumar Rasania ${ }^{5}$}

${ }^{1}$ Post Graduate, Department of Community Medicine, Lady Hardinge Medical College, New Delhi, Delhi 110001; ${ }^{2}$ Professor, Department of Community Medicine, Lady Hardinge Medical College, New Delhi, Delhi 110001; ${ }^{3}$ Professor, Department of Community Medicine, Lady Hardinge Medical College, New Delhi, Delhi 110001; ${ }^{4}$ Head, Department of Epidemiology \& Public Health, National Institute of TB \& Respiratory Diseases, Delhi-110030; ${ }^{5}$ Professor \& Head, Department of Community Medicine, Lady Hardinge Medical College, New Delhi, Delhi 110001

\begin{tabular}{|c|c|c|c|c|c|c|c|}
\hline Abstract & Introduction & Methodology & Results & Conclusion & References & Citation & Tables / Figures \\
\hline \multicolumn{8}{|c|}{ Corresponding Author } \\
\hline \multicolumn{7}{|c|}{$\begin{array}{l}\text { Dr. Khalid Umer Khayyam, National Institute of TB \& Respiratory Diseases, Delhi-110030 } \\
\text { E Mail ID: } \underline{\text { dr.khaliduk@yahoo.com }}\end{array}$} & 回粡回 \\
\hline
\end{tabular}

\section{Citation}

Kamaraj A, Goel MK, Khandekar J, Khayyam KU, Rasania SK Delay in diagnosis and treatment among registered TB patients in Directly Observed Treatment Short Course cum Designated Microscopy Centres in South Delhi. Indian J Comm Health. 2021;33(2):344-350. https://doi.org/10.47203/IJCH.2021.v33i02.021

Source of Funding: Delhi State RNTCP Conflict of Interest: None declared

\section{Article Cycle}

Received: 22/01/2021; Revision: 13/05/2021; Accepted: 04/06/2021; Published: 30/06/2021

This work is licensed under a Creative Commons Attribution 4.0 International License.

\section{Abstract}

Background: Knowing delays in treatment seeking and subsequent treatment initiation among the TB patients is important and its detailed understanding is crucial in modifying the treatment seeking behaviour which can help in reducing the TB burden and the transmission in the community. Aim \& Objective: To study the treatment seeking behaviour including the delays in initiation of treatment along with its determinants; among tuberculosis patients aged $>15$ years in Mehrauli area of Delhi. Settings and Design: A longitudinal follow up study conducted in two randomly selected DMC cum DOTS centres in Mehrauli area of Delhi from January 2018 to April 2018. Methods and Material: Patients of both sexes of age $>15$ years, registered under RNTCP from January to April 2018 in the randomly selected DOTS centres i.e. Mehrauli DMC cum DOTS and Chattarpur DMC cum DOTS centre were included in the study. Self-designed, pretested interview schedule and records of DMC were used to collect the relevant information. Statistical analysis used: Information collected in the Performa was coded and entered in Statistical Package for Social Sciences (SPSS) version 12. Results: The mean patients delay, diagnostic delay, treatment delay, health care system delay and total delay was $48.91 \pm 130.38$ days, $91.09 \pm 155.97$ days, $6.25 \pm 6.29$ days, $62.72 \pm 119.48$ days and $97.33 \pm 155.06$ days respectively. The median patients delay, diagnostic delay, treatment delay, health care system delay and total delay was 15 days, 45 days, 5 days, 35 days and 54 days respectively. Conclusions: The major reasons for patient's delay were lack of awareness regarding the symptoms of TB and self-medication and for health care system delay it was treatment from private health care providers.

\section{Keywords}

Tuberculosis; RNTCP; Patients Delay; Health Care System Delay.

\section{Introduction}

Early detection of cases and complete treatment are fundamental for effective TB control. Delays in seeking treatment, diagnosis and initiation of treatment may not have the ideally desired patient outcome and might also result in increased risk of transmission. $(1,2)$ The delays may be attributable to patient themselves and also related to TB control programme.
RNTCP in the past was based on passive case finding which in-turn depends on treatment seeking behaviour and related delays. Systematic review on treatment seeking behaviour among TB patients showed $50-80 \%$ sought medical care at private health facilities in India and most of them were not aware of national programs for TB. Moreover, there was significant delay reported among them; mean patient delay in treatment seeking ranged from 25 to 120 days.(3) 
Recently RNTCP had introduced active case finding strategies as per National strategic plan 2017-25, with a vision of TB-Free India with zero deaths by 2025.(4) It is therefore, important to identify and study these delays in order to make RNTCP more effective. The present study was conducted to identify delays and reasons thereof; among individual registered under RNTCP in Mehrauli area of Delhi.

\section{Aims \& Objectives}

To study the treatment seeking behaviour including the delays in initiation of treatment along with its determinants; among tuberculosis patients aged > 15 years in Mehrauli area of Delhi.

\section{Material \& Methods}

The National Tuberculosis Programme (NTP) was implemented in 1962 by Government of India which did not make a measurable impact on the disease situation of TB in the country. WHO declared TB as a global health emergency in April 1993 and developed a five-point strategy known as Directly Observed Treatment Short Course (DOTS) strategy.(5) Henceforth, the Government of India also evolved a revised strategy and launched the RNTCP based on DOTS strategy in 1997 and the nationwide coverage was achieved in March 2006.(6) The organogram of RNTCP includes various National level apex institutes, District TB centres, Drug Resistance TB centres. Tuberculosis unit and Designated Microscopy centres as shown in the (Figure 1).

The study was conducted in Mehrauli, located in South Delhi, among the two randomly selected Designated Microscopy centres (DMC) cum (DOTS) centres i.e. Mehrauli DMC cum DOTS centre and Chattarpur DMC cum DOTS centre by using lottery method among the four centres in the study area which provides facility for diagnosis, as per RNTCP guidelines. These two DMC cum DOTS centres were directly under the supervision of National Institute of TB and Respiratory Diseases-Revised National Tuberculosis Control Programme (NITRD-RNTCP) chest clinic. NITRD-RNTCP chest clinic formerly known as Lala Ram Swarup (LRS) Institute of Tuberculosis and Respiratory Diseases is one of the apex institute related to Tuberculosis treatment and research, in Delhi and also one of the six National Reference Labs for TB in India.

The identification data was collected from the records of Mehrauli and Chattarpur DMC cum DOTS centres. Then the study subjects were traced back to their respective residence. After the rapport has been established with the study subjects, they were informed about the purpose of the study and about the confidentiality of the data collected. After taking the written informed consent/assent from all the study subjects/guardians, the data was collected using a self-designed, pre-tested and semi structured schedule at their respective houses within 2 weeks of enrollment in the respective DOTS centre.
Ethical issues: Permission to carry out the study was obtained from the Institutional Board of studies and Institutional Ethical Committee, Lady Hardinge Medical College, New Delhi. Permissions were also sought from Delhi State Tuberculosis Office and NITRD-RNTCP chest clinic.

Study design: A community based longitudinal study was conducted among a total of 134 study subjects registered under RNTCP from January to April 2018: in the two randomly selected DMC cum DOTS centres in Mehrauli area of Delhi.

Study population: Patients of age $>15$ years registered under RNTCP (from January 2018 to April 2018) in the selected DMC cum DOTS centres were included in the study. The sample size was calculated by assuming the delay to be $60 \%$ with the help of previous studies (7) at $95 \%$ level of significance and $15 \%$ allowable error; which comes out to be 132 . All the patients registered under selected dots centres fulfilling the Inclusion and exclusion criteria were selected irrespective of sputum smear positivity or site of the disease i.e. pulmonary or extrapulmonary TB. A total of 170 patients were registered in the two selected DMC cum DOTS centres and among them 134 were enrolled for the study. The reasons for exclusion of 36 patients are shown in the (Figure 2).

Statistical analysis: Information collected in the Performa was coded and entered in Statistical Package for Social Sciences (SPSS) version 12. The qualitative variables were expressed in proportion and quantitative variables were summarized by mean and standard deviation. Binary logistic regression was also applied to find any sociodemographic determinants for delays.

Definitions used: The standard definitions were used to comment on various types of delay as follows.

Diagnostic delay: The time interval between the onset of TB symptoms and labeling of the patient as a Tuberculosis patient (tuberculosis diagnosis).(8)

Health care system delay: Time interval between the date of first consultation of TB suspect to a professional health care provider and the initiation of anti-tuberculosis treatment.(8)

Patients' delay: Time interval between onset of symptoms and first consultation with a professional health care provider.(8)

Treatment delay: Time interval between tuberculosis diagnosis and initiation of anti-tuberculosis drugs.(8)

Total delay: The Total delay is the sum of patient and healthcare system delay.(8)

\section{Results}

Sociodemographic characteristics: Almost equal proportion of males (49.3\%) and females (50.7\%) were found in the study. More than half (59\%) of the patients belonged to the age group 15-30 years. The mean age of the study subjects was found to be $31.73 \pm 13.74$ years (Range $15-78$ years). More than $60 \%$ of the study subjects 
had completed education up to high school. Approximately $2 / 3 \mathrm{rd}$ (69.4\%) of the study subjects belonged to Upper lower and Lower middle socioeconomic status. Majority i.e. $70 \%$ of the study subjects belonged to nuclear families. [Table 1]

Patients delay: Approximately half of the study subjects sought treatment within 2 weeks of symptoms which was more common among pulmonary TB patients and nearly $35 \%$ of the study subjects sought treatment after 4 weeks of symptoms which was more common among extrapulmonary TB patients. The proportion of subjects having delay of more than 4 weeks were more in females as compared to males for both pulmonary and extrapulmonary TB cases. The overall mean patients delay and median patients delay was $48.91 \pm 130.38$ days (Range 11095 days) and 15 days respectively. The mean delay was more among the extra-pulmonary cases (88.21 \pm 184.32 days and Range 1-1095 days) when compared to the pulmonary cases (15.14 \pm 13.85 days and Range 2-60 days). The median patients delay among pulmonary TB was 10 days and extra-pulmonary TB was 30 days. [Table 2] and [Table 7]

The reasons for patient's delay among the study subjects were lack of awareness regarding the symptoms of TB $(49.2 \%)$, self-medication (43.3\%), lack of accessibility (4.5\%) and busy working schedule (3\%). [Table 3].

On performing binary regression analysis, it was found that none of the socio-demographic factors such as age, sex, type of family, literacy of the patient, alcohol and tobacco usage were significantly associated with patients delay indicating that the all the patients had low level of awareness irrespective of their sociodemographic variables. [Table 4]

Diagnostic delay: Approximately $47 \%$ of the study subjects were diagnosed after 2 months of symptoms which was more among the extra-pulmonary cases. Overall mean diagnostic delay was 91.09 days +155.97 days (Range 6 to 1155 days). The delay was more in pulmonary TB cases (54.96 \pm 33.95 days range 8-150 days) as compared to extra-pulmonary cases (133.05 \pm 218.39 days, Range 6-1155 days). The proportion of subjects having diagnostic delay more than 1 month were more in females $(39.5 \%)$ as compared to males (32.8\%) for both pulmonary (18.6\%-vs-17.9\%) \& extra-pulmonary TB cases (20.9\%-vs-14.9\%). Overall median diagnostic delay was 45 days (60 days for pulmonary TB-vs- 45 days in extrapulmonary TB). [Table 5 \& Table 7]

Health care System delay: Mean Health care system delay among pulmonary TB and extra-pulmonary TB was 55.99 + 101.96 days (Range 3 to 866 days) and $70.53+137.51$ days (Range 0-666 days) respectively and overall mean health care system delay was $62.72 \pm 119.48$ days (Range 0-866 days). The median health care system delay was 35 days which was less among extra-pulmonary TB (25 days) than that of pulmonary TB (40 days). [Table 7]
Treatment delay: Majority (80.6\%) of the patients started treatment within 7 days of diagnosis. Only very few patients (19.4\%) were started treatment after 2 weeks of diagnosis which was common among the pulmonary TB. The treatment delay was approximately similar in males and females in pulmonary TB but in extra-pulmonary TB males started treatment without any delay while in women treatment was delayed. Mean treatment delay among pulmonary cases was $7.54 \pm 7.53$ days (Range $0-44$ days) and among extra-pulmonary cases was $4.76 \pm 4$ days (Range 0-28 days) and the overall treatment delay was $6.25+6.29$ days (Range $0-44$ days). The overall median treatment delay was 5 days and which was same in pulmonary TB (5 days) while in extra-pulmonary it was 4 days. [Table 6 \& Table 7]

Total delay: Mean total delay was $97.33 \pm 155.06$ days and median total delay was 54 days. Among extra-pulmonary cases mean total delay (137.74 \pm 219.04 days) was more than the pulmonary cases $(62.53+34.08$ days $)$. [Table 7]

\section{Discussion}

As RNTCP program me also mainly stresses on passive case surveillance it is very important to address the patients delay since it is impossible to diagnose TB unless and until patient willingly seeks the treatment and reports to the health care delivery system.

Patients delay: Delayed reporting by the patients results in delay in diagnosis and also subsequent initiation of treatment. It is commonly seen that delay worsens the disease. Pulmonary TB cases tend to report early to the health care provider because of persistence of symptoms as compared to extra-pulmonary cases where the tendency is to delay the treatment as symptoms are vague or may be mild. In the present study, nearly half (50\%) of the study subjects sought treatment within 2 weeks which was more common among pulmonary cases i.e. more than $60 \%$ of the pulmonary cases sought treatment within 2 weeks of symptoms. Approximately $64 \%$ of the study subjects sought treatment within 4 weeks and similar findings was seen in a study carried out by selvam et al.(9) Approximately $1 / 3$ rd of the study subjects sought treatment $>4$ weeks of symptoms which was similar to findings of Nimbarte et al(10) and it was more common among the extra-pulmonary cases. The mean delay was more among the extra-pulmonary cases when compared to pulmonary cases and similar results was found by Ananthakrishnan et al.(11) The reason might be that the extra-pulmonary patients don't perceive those symptoms as of TB or they don't take it seriously which might be the reason for their late presentation to the health facilities. The delay was more among the female study subjects when compared to males and similar results was found by Samera et al,(12) Kapoor et al(13) and Ashutosh et al.(14) The reason may be that the health condition of females is not given much importance in the society and most of the times they are treated with self-medications i.e. chemist 
shop. In the present study most of the subjects belonged to a nuclear family and husband remained on duty so no one was available to take the female study subjects to a health care facility as soon as possible.

Overall mean patients delay was $48.91+130.38$ days and similar results was reported by F.Maamari et al(15) The median patient delay was 15 days and similar results were found by Nimbarte et al,(10) Ashutosh et al,(14) Belay et al,(16) Selvam et al(17 )and Beheracor et al.(18)

Diagnostic delay: Diagnostic delay is the combination of patients delay and health care system delay. So the reason for delay is attributed to both patient and health care providers. Most of the times the first contact for the patient with the health care system is the private health care provider. In our study approximately $63 \%$ patients reported to private practitioners for first consultation and similar results were found in various other studies such as Ananthakrishnan et al,(11) Maamari et al,(15) Awol Hussen et al,(19) Van wyk et al,(20) Zerbini et al,(21) Karenjekar et al,(22) Kulkarni et al,(23) and Charles et al.(24) Among the private health providers, 33\% was either unqualified or their qualification of those practioners could not be ascertained.

Overall mean diagnostic delay was $91.09+155.97$ days and similar results were found by E.Zerbini et al.(21) The median diagnostic delay was 45 days while various other studies $(15,17,25,26)$ reported the median diagnostic delay ranging from 33 days to 55 days.

Treatment delay: Only very few patients (19.4\%) were initiated treatment after 2 weeks of diagnosis. Similar results were reported by Beheracor et al.(18) This delay of 2 weeks or more was common among the pulmonary cases than the extra-pulmonary. The finding may be explained based on the fact that in pulmonary cases, it took 2-3 days for patients to collect the report. The day on which sputum has been sent for these patients was defined as the day 1 while for extra-pulmonary the day of referral was considered as the day 1 as they were diagnosed after extensive workup. The mean treatment delay among pulmonary cases was $7.544+7.53$ days and in extra-pulmonary was $6.25+6.29$ days. Overall mean treatment delay was $6.25+6.29$ days and there is still so much scope to minimize this further. The overall median treatment delay was 5 days and which was same in pulmonary cases while in extra-pulmonary cases it was 4 days and similar result was found by F. Maamari et al,(15) Belay et al,(16) Awol Hussen et al,(19) S.S. Van wyk et al,(20) and Thakur et al.(26)

Total delay: The overall mean total delay was $97.33+$ 155.06 days and the median total delay was 54 days. Similar results were found in the various studies. $(15,21,27,28)$ On the other hand in other studies $(12,19,20,26,29,30)$ the total delay varied from 31 to 97 days. Most of the studies have reported a longer total delay as compared to present study, where total delay was mainly contributed by diagnostic delay i.e. patients delay and part of health care system delay. The delay for initiation was found to be minimal in present study as the centres were directly under supervision of NITRD-RNTCP Chest clinic, which is one of the apex institutes in the country. Total delay is an important public health issue as it results in increasing transmission as well as complicated cases of TB. Increasing awareness about signs, symptoms and treatment of TB among general population will help in addressing the issue of delay in seeking treatment.

\section{Conclusion}

Among the delays the health care system delay due to private practitioners and patients delay were found to be of higher which poses a serious threat to the society.

The main reasons for delay were lack of awareness regarding the symptoms of $\mathrm{TB}$, other reasons were selfmedication, lack of accessibility and busy working schedule, treatment from unqualified medical practitioner etc.

As mentioned earlier $33 \%$ of the patients consulted the unqualified private practitioners and they were either not evaluated properly or given wrong treatment for months which is one of the important reasons for delay that must be taken care of.

In most of the cases the health care system delay was related to the patients initially go to private practitioners and these practitioners give false assurance to cure the disease within a month but that never happen. After that patients approach to DMCs where only availability of sputum by ZN method of the diagnostic facilities and take long waiting period to receive reports of referred patients to start treatment.

The treatment delay was seen mainly because of the existence of referral system from the tertiary hospitals to the DOTS centres near to their home. In case the diagnosis is made in peripheral units it is minimized as diagnosis and treatment is carried out by the same institution. The delay is more if diagnosis is made in a tertiary care institution, more time is wasted in consultation and referral to nearest DOTS centre, where the patient resides. As per guidelines, the DOTS provider is required to visit the patients home before initiation of treatment which delays the initiation by two to three days due to higher work load of the workers.

This study was carried out in urban area with wellfunctioning tertiary care set-ups like NITRD, All India Institute of Medical College and Safdarjung hospitals yet the patients preferred private health care providers to save time over these government tertiary hospitals due to exhaustive OPD line-ups and the delayed date for the diagnostic work-ups/investigations in these facilities.

\section{Recommendation}

In order to achieve the goal of TB elimination by 2025, scaling up the services and identify key stakeholders is a must. In relation to TB management the patient 
themselves, health care providers along with the government are the main stakeholders. therefore, government should take up the responsibility of improving awareness among population and sensitizing all public and private health care providers involved in management of TB.

\section{Limitation of the study}

Since the study was conducted in the urban area only, the treatment seeking behaviour may differ in the rural settings and so findings cannot be generalized. There are many specialized institutes related to management of TB in the study area i.e. NITRD-RNTCP chest clinic which is one of the national reference labs, so the patients might have a good access to quality health care services which may not be the scenario in other settings

\section{Relevance of the study}

This study has thrown some light over the different types of delay and the health seeking behaviour among the TB patients. Still the major reason for patients delay is lack of awareness, which is an alarming finding since our country is considered to be the TB capital of the world.

\section{Authors Contribution}

All authors contributed equally.

\section{Acknowledgement}

We sincerely thank Dr. Ashwani Khanna, STO for granting permission and providing a grant of Rs. 30,000 for the postgraduate thesis under Delhi State RNTCP.

\section{References}

1. Sreeramareddy CT, Qin ZZ, Satyanarayana S, Subbaraman R, Pai M. Delays in diagnosis and treatment of pulmonary tuberculosis in India: a systematic review. Int J Tubercul Lung Dis. 2014;18:255-66.

2. Yimer S, Holm-Hansen C, Yimaldu T, Bjune G. Health care seeking among pulmonary tuberculosis suspects and patients in rural Ethiopia: a community-based study. BMC public health.2009;9:454.

3. SaMal J. Health Seeking Behaviour among Tuberculosis Patients in India: A Systematic Review. J Clin Diagn Res.2016;10(10):LE01.

4. Revised National TB Control Programme (RNTCP) National Strategic Plan for Tuberculosis Elimination 2017-2025. New Delhi, India: Central TB Division Government of India; 2017 Mar: 6.

5. Kaur G, Goel NK, Kumar D, Janmeja AK, Swami HM, Kalia M. Treatment outcomes of patients placed on treatment under directly observed therapy short-course (dots). Lung India. 2008;25(2):75-7

6. Jain M, Swarnkar M, Mehta SC, Kumar V. Evaluation study of treatment outcome in Tuberculosis patients receiving DOTS under RNTCP. Indian $J$ Community Health. 2016;28(4):352-8.

7. Kulkarni PY, Kulkarni AD, Akarte SV, Bhawalkar JS, Khedkar DT. Treatment seeking behaviour and related delays by pulmonary TB patients in E-ward of Mumbai Municipal Corporation, India. Int J Med Public Health. 2013; 3:286-92.

8. WHO. Diagnostic and treatment delay in tuberculosis. An in-depth analysis of the health-seeking behaviour of patients and health system response in seven countries of the Eastern Mediterranean Region. Cairo: World Health Organization; 2006;14.

9. Selvam J M, Wares F, Perumal M, Gopi P G, Sudha G, Chandrasekaran $V$, et al. Health-seeking behaviour of new smear-positive TB patients under a DOTS programme in Tamil Nadu, India, 2003. Int J Tuberc Lung Dis. 2007; 11: 161-67.
10. Nimbarte SB, Wagh V, Selokar D. Health seeking behaviour among pulmonary TB patients in rural part of central India. Int J Biol Med Res. 2011;2:394-97.

11. Ananthakrishnan R, Jeyaraju A R, Palani G, Sathiyasekaran BWC. Care seeking behaviour of the TB patients who were registered in an urban government TB Control in Chennai, Tamilnadu, India. J Clin Diagn Res. 2012; 6:990-93.

12. Qureshi SA, Morkve O, Mustafa T. Patient and health system delays: health-care seeking behaviour among pulmonary tuberculosis patients in Pakistan. JPMA. J Pak Med Assoc. 2008; 58:318.

13. Kapoor SK, Raman AV, Sachdeva KS, Satyanarayana S. How did the TB patients reach DOTS services in Delhi? A study of patient treatment seeking behavior. PLoS one. 2012; 7:e42458.

14. Tamhane A, Ambe G, Vermund SH, Kohler CL, Karande A, Sathiakumar N. Pulmonary tuberculosis in Mumbai, India: factors responsible for patient and treatment delays. Int J Prev Med. 2012; 3:569.

15. Maamari F. Case-finding tuberculosis patients: diagnostic and treatment delays and their determinants. East Mediterr Health J 2008; 14:531-45.

16. Belay M, Bjune G, Ameni G, Abebe F. Diagnostic and treatment delay among Tuberculosis patients in Afar Region, Ethiopia: a cross-sectional study. BMC Public Health. 2012; 12:369.

17. Selvam Paramasivam BT, Chandran P, Thayyil J, George B, Sivakumar CP. Diagnostic delay and associated factors among patients with pulmonary tuberculosis in Kerala. J Family Med Prim Care. 2017; 6:643.

18. Behera BK, Jain RB, Gupta KB, Goel MK. Extent of delay in diagnosis in new smear positive patients of pulmonary tuberculosis attending tertiary care hospital. Int J Prev Med. 2013; 4:1480.

19. Hussen A, Biadgilign S, Tessema F, Mohammed S, Deribe K, Deribew A. Treatment delay among pulmonary tuberculosis patients in pastoralist communities in Bale Zone, Southeast Ethiopia. BMC Res Notes. 2012; 5:320.

20. Van Wyk SS, Enarson DA, Beyers N, Lombard C, Hesseling AC. Consulting private health care providers aggravates treatment delay in urban South African tuberculosis patients. Int J Tuberc Lung Dis. 2011; 15:1069-76.

21. Zerbini E, Chirico MC, Salvadores B, Amigot B, Estrada S, Algorry G. Delay in tuberculosis diagnosis and treatment in four provinces of Argentina. Int J Tuberc Lung Dis. 2008; 12:63-8.

22. Karanjekar VD, Gujarathi VV, Lokare PO. Socio demographic factors associated with health seeking behaviour of chest symptomatics in urban slums of Aurangabad city, India. Int J App Basic Med Res. 2014; 4:173-79.

23. Kulkarni PY, Kulkarni AD, Akarte SV, Bhawalkar JS, Khedkar DT. Treatment seeking behaviour and related delays by pulmonary TB patients in E-ward of Mumbai Municipal Corporation, India. Int J Med Public Health. 2013; 3:286-92.

24. Charles N, Thomas B, Watson B, Chandrasekeran V, Wares F. Care seeking behaviour of chest symptomatics: a community based study done in South India after the implementation of the RNTCP. PloS one. 2010; 5:e12379.

25. Meyssonnier V, Li X, Shen X, Wang H, Li DY, Liu ZM, Liu G, Mei J, Gao Q. Factors associated with delayed tuberculosis diagnosis in China. Eur J Public Health. 2013;23(2):253-7.

26. Thakur R, Murhekar M. Delay in diagnosis and treatment among TB patients registered under RNTCP Mandi, Himachal Pradesh, India, 2010. Indian J Tuberc. 2013;60(1):37-45

27. Saqib MA, Awan IN, Rizvi SK, Shahzad MI, Mirza ZS, Tahseen S, Khan IH, Khanum A. Delay in diagnosis of tuberculosis in Rawalpindi, Pakistan. BMC Res Notes. 2011;26(4):165. doi: 10.1186/1756-0500-4-165. PMID: 21615946; PMCID: PMC3123219.

28. Aye $\mathrm{R}$, Wyss $\mathrm{K}$, Abdualimova $\mathrm{H}$, Saidaliev $\mathrm{S}$. Patient's site of first access to health system influences length of delay for tuberculosis treatment in Tajikistan. BMC Health Serv Res. 2010; 10:10.

29. Ukwaja KN, Alobu I, Nweke CO, Onyenwe EC. Healthcare-seeking behavior, treatment delays and its determinants among pulmonary tuberculosis patients in rural Nigeria: a cross-sectional study. BMC Health Serv Res. 2013; 13:25.

30. Gele AA, Bjune G, Abebe F. Pastoralism and delay in diagnosis of TB in Ethiopia. BMC Public Health. 2009; 9:5. 
Tables

TABLE 1 SOCIODEMOGRAPHIC PROFILE OF STUDY SUBJECTS ( $\mathrm{N}=134)$

\begin{tabular}{|c|c|c|c|}
\hline \multicolumn{2}{|c|}{ Socio demographic character } & \multirow{2}{*}{$\begin{array}{l}\text { Total }(\mathrm{N}=134) \\
66\end{array}$} & \multirow{2}{*}{$\begin{array}{l}\text { Percentage } \\
49.3\end{array}$} \\
\hline Sex & Male & & \\
\hline & Female & 68 & 50.7 \\
\hline \multirow{4}{*}{$\begin{array}{l}\text { Age (in completed } \\
\text { years) }\end{array}$} & $15-30$ & 79 & 59 \\
\hline & $31-45$ & 30 & 22.4 \\
\hline & $46-60$ & 20 & 14.9 \\
\hline & $\geq 61$ & 05 & 3.7 \\
\hline \multirow[t]{6}{*}{ Literacy level } & Illiterate & 06 & 4.5 \\
\hline & Literate, less than Primary school & 22 & 16.4 \\
\hline & Middle school & 22 & 16.4 \\
\hline & High school & 31 & 23.1 \\
\hline & Higher secondary / Diploma & 25 & 18.7 \\
\hline & Graduate/Post graduate/Professional & 28 & 20.9 \\
\hline \multirow{3}{*}{$\begin{array}{l}\text { Socio- } \\
\text { economic } \\
\text { status }\end{array}$} & Upper Lower (IV) & 43 & 32.1 \\
\hline & Lower Middle (III) & 50 & 37.3 \\
\hline & Upper middle (II) \& Upper (I) & 41 & 30.6 \\
\hline \multirow[t]{2}{*}{ Type of family } & Nuclear & 94 & 70.1 \\
\hline & Joint & 40 & 29.9 \\
\hline
\end{tabular}

TABLE 2 PATIENTS DELAY ACCORDING TO SEX AND TYPE OF TB AMONG STUDY SUBJECTS ( $N=134$ )

\begin{tabular}{|c|c|c|c|c|c|c|c|c|c|}
\hline \multirow[t]{2}{*}{ Patients delay* } & \multicolumn{3}{|c|}{ Pulmonary n=72 No. (\%) } & \multicolumn{3}{|c|}{ Extra-pulmonary n=62 №. (\%) } & \multicolumn{3}{|c|}{ Total N=134 No. (\%) } \\
\hline & Male & Female & Total & Male & Female & Total & Male & Female & Total \\
\hline No delay (<2 weeks) & $25(55.6)$ & $20(44.4)$ & 45 & $11(50)$ & $11(50)$ & 22 & 36 (53.7) & $31(46.3)$ & $67(50)$ \\
\hline 2- 4 Weeks & $6(50)$ & $6(50)$ & 12 & $2(28.6)$ & $5(71.4)$ & 7 & $8(42.1)$ & 11 (57.9) & 19 (14.2) \\
\hline$\geq 4$ weeks & $7(46.7)$ & $8(53.3)$ & 15 & $15(45.5)$ & $18(54.5)$ & 33 & $22(45.8)$ & $26(54.2)$ & 48 (35.8) \\
\hline
\end{tabular}

\section{TABLE 3 REASONS FOR PATIENTS DELAY ( $=134)$}

\begin{tabular}{|ll}
\hline Reasons & Number (\%) \\
\hline Self-medication & $66(49.2)$ \\
\hline Lack of accessibility & $58(43.3)$ \\
\hline Busy working schedule & $6(4.5)$ \\
\hline
\end{tabular}

TABLE 4 EFFECTS OF VARIOUS SOCIO-DEMOGRAPHIC FACTORS ASSOCIATED WITH PATIENTS DELAY

\begin{tabular}{|c|c|c|}
\hline Socio-demographic factors & Significance & $\operatorname{Exp}(B)$ \\
\hline Sex & 0.179 & 1.839 \\
\hline Age & 0.881 & 0.965 \\
\hline Literacy level of the patient & 0.268 & 0.648 \\
\hline Type of Family & 0.731 & 1.159 \\
\hline Alcohol & .703 & 1.220 \\
\hline Tobacco & .204 & 1.916 \\
\hline
\end{tabular}

TABLE 5 DIAGNOSTIC DELAY ACCORDING TO SEX AND TYPE OF TB AMONG STUDY SUBJECTS (N=134)

\begin{tabular}{|c|c|c|c|c|c|c|c|c|c|}
\hline \multirow{2}{*}{$\begin{array}{l}\text { Diagnostic } \\
\text { delay* }\end{array}$} & \multicolumn{3}{|c|}{ Pulmonary (n=72) No. (\%) } & \multicolumn{3}{|c|}{ Extra-pulmonary (n=62) No. (\%) } & \multicolumn{3}{|c|}{ Total (N=134) No. (\%) } \\
\hline & Male & Female & Total & Male & Female & Total & Male & Female & Total \\
\hline$\leq 1$ Month & $14(60.9)$ & $9(39.1)$ & 23 & $8(57.1)$ & $6(42.9)$ & 14 & $22(59.5)$ & $15(40.5)$ & $37(27.6)$ \\
\hline 1-2 Months & $7(35)$ & $13(65)$ & 20 & $7(50)$ & $7(50)$ & 14 & $14(41.2)$ & $20(58.8)$ & $34(25.4)$ \\
\hline 2-3 Months & $6(54.5)$ & $5(45.5)$ & 11 & $4(44.4)$ & $5(55.6)$ & 9 & $10(50)$ & $10(50)$ & 20 (14.9) \\
\hline$>3$ Months & $11(61.1)$ & $7(38.9)$ & 18 & $9(36)$ & $16(64)$ & 25 & $20(46.5)$ & $23(53.5)$ & $43(32.1)$ \\
\hline
\end{tabular}




\begin{tabular}{|c|c|c|c|c|c|c|c|c|c|}
\hline \multirow{2}{*}{$\begin{array}{l}\text { Treatment } \\
\text { delay* }\end{array}$} & \multicolumn{3}{|c|}{ Pulmonary (n=72) No. (\%) } & \multicolumn{3}{|c|}{ Extra-pulmonary (n=62) No. (\%) } & \multicolumn{3}{|c|}{ Total (N=134) No. (\%) } \\
\hline & Male & Female & Total & Male & Female & Total & Male & Female & Total \\
\hline $\begin{array}{l}<7 \text { days } \\
\text { (No delay) }\end{array}$ & 27 (52.9) & $24(47.1)$ & 51 & 28 (49.1) & $29(50.9)$ & 57 & $55(50.9)$ & 53 (49.1) & $\begin{array}{l}108 \\
(80.6)\end{array}$ \\
\hline 7- 14 days & $3(30)$ & $7(70)$ & 10 & 0 & $3(100)$ & 3 & $3(23.1)$ & $10(76.9)$ & $13(9.7)$ \\
\hline$\geq 14$ days & $8(72.7)$ & $3(27.3)$ & 11 & 0 & $2(100)$ & 2 & $8(61.5)$ & $5(38.5)$ & $13(9.7)$ \\
\hline
\end{tabular}

\begin{tabular}{|c|c|c|c|c|}
\hline \multirow{2}{*}{ Type of Delay } & & Pulmonary & Extra-pulmonary & Total \\
\hline & \multirow{3}{*}{ Mean \pm SD (Range) } & $(n=72)$ & $(n=62)$ & $(N=134)$ \\
\hline \multirow[t]{3}{*}{ Patients delay } & & $15.14 \pm 13.85$ & $88.21 \pm 184.32$ & $48.91 \pm 130.38$ \\
\hline & & $(2-60)$ & (1-1095) & (1 to 1095$)$ \\
\hline & Median (Days) & 10 & 30 & 15 \\
\hline \multirow[t]{3}{*}{ Diagnostic delay } & \multirow[t]{2}{*}{ Mean \pm SD (Range) } & $54.96 \pm 33.95$ & $133.05 \pm 218.39$ & $91.09 \pm 155.97$ \\
\hline & & $(8-150)$ & $(6-1155)$ & (6 to 1155 ) \\
\hline & Median (Days) & 45 & 60 & 45 \\
\hline \multirow[t]{3}{*}{ Treatment delay } & \multirow[t]{2}{*}{ Mean \pm SD (Range) } & $7.54 \pm 7.53$ & $4.76 \pm 4$ & $6.25 \pm 6.29$ \\
\hline & & $(0-44)$ & $(0-28)$ & $(0-44)$ \\
\hline & Median (Days) & 5 & 4 & 5 \\
\hline \multirow[t]{3}{*}{ Health care system delay* } & \multirow[t]{2}{*}{ Mean \pm SD (Range) } & $55.99 \pm 101.96$ & $70.53 \pm 137.51$ & $62.72 \pm 119.48$ \\
\hline & & $(3-866)$ & $(0-666)$ & $(0-866)$ \\
\hline & Median (Days) & 40 & 25 & 35 \\
\hline \multirow[t]{3}{*}{ Total delay" } & \multirow[t]{2}{*}{ Mean \pm SD (Range) } & $62.53 \pm 34.08$ & $137.74 \pm 219.04$ & \multirow[t]{2}{*}{$97.33 \pm 155.06(10-1157)$} \\
\hline & & $(13-50)$ & $(10-1157)$ & \\
\hline & Median (Days) & 53 & 66 & 54 \\
\hline
\end{tabular}

\section{Figures}

FIGURE 1 ORGANIZATIONAL STRUCTURE OF RNTCPROGRAMME, INDIA

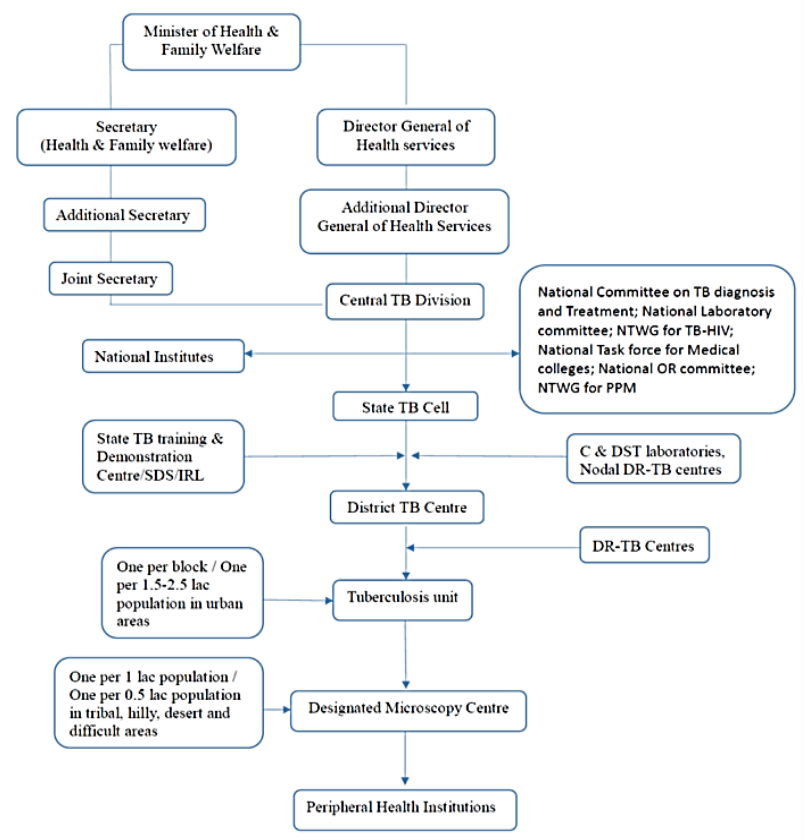

FIGURE 2 THE SELECTION OF CASES FROM THE DOTS CENTRES

Patients registered under RNTCP in two selected Microscopy cum DOTS centres

Total cases registered -170

Total cases taken -134

Total cases excluded- 36

Reasons for exclusion:

Patients less than 15 years old

Those who did not give consent

MDR-TB

XDR-TB

Transferred out cases 